(c) American Dairy Science Association, 2005.

\title{
Letter to the Editor: Concerning an Article Comparing the Efficacy of Local and Systemic Treatment of Clinical Mastitis
}

\author{
Satu Pyörälä \\ Saari Unit, Department of Clinical Veterinary Medicine, Faculty of Veterinary Medicine, \\ University of Helsinki, 04920 Helsinki, Finland
}

I would like to comment on the article by Sérieys et al. (2005). Unfortunately, this study failed to reliably answer the question of the comparative efficacy of systemic vs. local treatment of clinical mastitis, despite the title. The study has a fundamental design oversight: The in vitro susceptibility of mastitis-causing bacteria was not taken into account. Susceptibility to the used antimicrobials is a prerequisite for successful treatment with antimicrobials, and treatment efficacy cannot be evaluated if this is neglected. In this study, one treatment, penethamate (which is changed to penicillin $\mathrm{G}$ in the body), is active only for $\beta$-lactamase-negative staphylococci. If treatment efficacy is studied in staphylococcal mastitis, it is very important to determine the $\beta$-lactamase status of the isolates to select the treatment, but as a confounding factor because it affects the prognosis (see Sol et al., 2000; Taponen et al., 2003). In the study by Sérieys et al. (2005), information about the $\beta$-lactamase status of staphylococci was not clearly defined; in vitro susceptibility of Staphylococcus aureus to penicillin G cannot be "intermediate," and furthermore, the in vitro susceptibility for penicillin $G$ and ampicillin (which is also degraded by $\beta$-lactamase) did not agree as they should, and some failure in the methodology is thus likely (see NCCLS, 2002).

The Soback et al. (1990) reference cited by Sérieys et al. (2005) on page 93 should not be cited here as these authors studied a drying-off treatment, but more important is that this old preliminary study should not be cited at all, as its results could not be confirmed and were later refuted in 1993 (Saran et al., 1993). In this

Received January 3, 2005.

Accepted February 3, 2005.

E-mail: satu.pyorala@helsinki.fi. update of the trial, systemic drying-off treatment was not found more efficient than conventional intramammary treatment. Unfortunately, this update has not been widely acknowledged.

I would very much like to see a true comparative study of local and systemic antimicrobial treatment of mastitis where 1) the isolates would be tested to be susceptible in vitro for the antimicrobials used; 2) in systemic treatment, a dose that would maintain therapeutic concentrations in the udder would be used [in most studies, underdosing is used and thus a fair evaluation cannot be made; this was the case in the study of Hillerton and Kliem (2002), which was also cited by Sérieys et al. (2005)]; and 3) the group size would be high enough for statistical comparison by bacteria. Then we might have an answer to the question of the comparative efficacy of systemic vs. local treatment.

\section{REFERENCES}

Hillerton, J. E., and K. E. Kliem. 2002. Effective treatments of Streptococcus uberis clinical mastitis to minimize the use of antibiotics. J. Dairy Sci. 85:1009-1014.

National Committee for Clinical Laboratory Standards (NCCLS). 2002. Performance standards for antimicrobial disk and dilution susceptibility tests for bacteria isolated from animals. Approved standards. 2nd ed. NCCLS Document M31-A2. NCCLS, Wayne, PA.

Saran, A., G. Ziv, and S. Soback. 1993. Systemic dry cow therapyAn update. IDF Mastitis News 134:18.

Sérieys, F., Y. Raguet, L. Goby, H. Schmidt, and G. Friton. 2005. Comparative efficacy of local and systemic antibiotic treatment in lactating cows with clinical mastitis. J. Dairy Sci. 88:93-99.

Soback, S., G. Ziv, M. Winkler, and A. Saran. 1990. Systemic dry cow therapy: A preliminary report. J. Dairy Sci. 73:661-666.

Sol, J., O. C. Sampimon, H. W. Barkema, and Y. H. Schukken. 2000. Factors associated with cure after therapy of clinical mastitis caused by Staphylococcus aureus. J. Dairy Sci. 83:278-284.

Taponen, S., A. Jantunen, E. Pyörälä, and S. Pyörälä. 2003. Efficacy of targeted 5-day combined parenteral and intramammary treatment of clinical mastitis caused by penicillin-susceptible or penicillin-resistant Staphylococcus aureus. Acta Vet. Scand. 44:53-62. 